It is a unit of mass, which can be defined by the statement that one atom of the carbon isotope ${ }^{12} \mathrm{C}$ has a mass of 12 daltons. Thus one dalton equals $\mathrm{N}^{-1} \mathrm{~g}=1.663 \times 10^{-24} \mathrm{~g}$, where $\mathrm{N}$ is Avogadro's numbor. This is obviously identical with the officially defined "unified atomic mass unit" or a.m.u. ${ }^{2}$. It is also identical with the "avogram", a name proposed for this mass unit in 1949, approved in 1950 by the American Chemical Society on the recommendation of its Committee on the Nomenclature of Physical Chem. istry (chairman, T. F. Young) ${ }^{3}$.

What is meant by molecular weight, and in what units is it to be expressed? The Commission on PhysicoChemical Symbols, Terminology and Units (I.1) of the IUPAC Physical Chemistry Division considers "molecular weight" to be the relative molecular mass of a substance, that is, the ratio of the mass of one molecule of the substance to one-twelfth the mass of an atom of ${ }^{12} \mathrm{C}$ (personal cornmunication from Dr Martin A. Paul, of the Division of Chemistry and Chemical Technology, National Research Council, Washington, DC ; secretary of Commission I.1 of the Physical Chemistry Division of IUPAC). It is therefore a pure number and is dimensionless. The Commission also defines the "molar mass", with symbol $M$, as the amount of a substance containing as many elementary units (properly specified by some formula such as $\mathrm{C}_{11} \mathrm{H}_{12} \mathrm{~N}_{2} \mathrm{O}_{2}$ ) as there are carbon atoms in exactly $0.012 \mathrm{~kg}$ of carbon-12. Thus molar mass is commonly expressed in $\mathrm{g}$ mole-1. Many references to "molecular weight" obviously mean a quantity which is identical with molar mass as already defined. For example, in the well-known Svedberg equation for the quantity $M$ from sedimentation coefficient $(s)$, diffusion coefficient $(D)$ and partial specific volume (v) (ref. 4):

$$
M=R T s / D(1-\hat{v} \rho)
$$

The same is, of course, true for $M$ as determined by measurements of osmotic pressure or other colligative properties. The dimensions of $M$ are $\mathrm{g}$ mole-1. Svedberg and Pedersen 4 and many other authors including myself ${ }^{5}$ have referred to $M$ as "molecular weight", and this usage, to my knowledge, has almost never been challenged. Clearly a mass in daltons is numerically identical with molar mass in $\mathrm{g} \mathrm{mole}^{-1}$, but it is clearly incompatible with the IUPAC definition of molecular weight.

One convenience of the dalton is that biochemists and cell biologists can describe structures for which the term "molecular weight" is inappropriate: ribosomes, mitochondria, other cellular organelles, bacteriophages, and so on. In 1959 , for example, Tissières et al ${ }^{6}$ reported the "molecular weight" of $70 \mathrm{~S}$ ribosomes from Escherichia coli as approximately $2 \cdot 6 \times 10^{6}$. But ribosomes are complex organized structures, containing many different kinds of protein molecules and several kinds of RNA molecules, and it would be more logical to say, "the mass of the $E$. coli ribosome is $2.6 \times 10^{6}$ daltons", so avoiding the implication that the ribosome is a molecule.

The unit is also useful to specify the mass of the unit cell of such erystals as those of proteins, which contain water and salts or other substances as well as the molecule of primary interest. Low ${ }^{7}$ used the avogram for this purpose in reporting her studies on serum albumin erystals. If $V$ is the volume of the unit cell in $\mathrm{cm}^{3}$, and $\rho$ is its density, then the mass of the unit cell in daltons is $N V$ p. Thus the mass of the unit cell of the "wet" human mercaptalbumin mercury dimer was 590,000 daltons, and analysis showed that $44 \cdot 6$ per cent of this was protein. Another use is in reporting the content of various substances in a cell. Thus a human lung cell has been reported to contain $6 \mathrm{pg}$ of $\mathrm{DNA}^{8}$, which corresponds to $3.6 \times 10^{12}$ daltons. The content of DNA in daltons, divided by the mean residue weight of the nucleotides in the DNA, also expressed in daltons, gives the number of nucleotides in the DNA of the cell.

I believe it would avoid confusion to maintain the IUPAC definition of "molecular weight" as a ratio. The term "relative molecular mass", as Dr Paul has pointed out, is a clearer expression of the nature of this quantity than is "molecular weight". 'Thus it would be correct to write: "the molar mass of protein $\mathrm{X}$ is $25,000 \mathrm{~g}$ "; or "the molecular mass of protein $\mathrm{X}$ is 250,000 daltons"; or "the relative molecular mass (that is, molecular weight) of protein $\mathrm{X}$ is 25,000 ". All these statements are different ways of expressing the same fundamental facts. It would, however, be incorrect to say: "the molecular weight of protein X is 25,000 daltons", for the dalton is a unit of mass, and molecular weight is dimensionless. I hope the nomenclature committees of IUPAC and of the International Union of Biochemistry will be stimulated to clarify these matters and to make investigators aware of the somewhat subtle distinctions involved.

Yours faithfully, John T. Edsalx

Biological Laboratories,

Harvard University,

Cambridge,

Massachusetts 02138.

${ }^{1}$ Handbook for Authors, 95 (American Chemical Society, Washington, 1967). 2 Bateman, G. M., et al., J. Chem. Educ., 26, 113 (1949).

- Crane, E. J., Chem. Eng. News, 28, 1841 (1950).

4 Svedberg, T., and Pedersen, K. O., The Oltracentrifuge, 5 (Oxford, 1940).

5 Cohn, E. J., and Edsall, J. T., Proteins, Amino Acids and Peptides, chap. 16, 17, 19 (Reinhold, New York, 1943; Hafner, New York, 1965).

6 Tissières, A., Watson, J. D., Schlessinger, D., and Hollingworth, B. R., J. Mol. Biol., 1, 221 (1959).

" Low, B. W., J. Amer. Chem. Soc., 74, 4830 (1952).

${ }^{8}$ Handbook of Biochemistry (edit. by Sober, H. A.), first ed., H-59 (Chemical Rubber, Cleveland, 1968).

\section{Another Review Journal}

SiR,--I have two points about R. J. Blin-Stoyle's review under the title "Another Review Journal" (Nature, 228, $390 ; 1970)$.

The "proliferation of journals" in physics is not adequate ground for not publishing more. This new periodical may be more useful than some already in existence.

Neither is the "sufficiency of natural homes" for each of the articles. The editors would presumably not have commissioned these articles if this periodical hadn't been published.

I suggest that many who deprecate new journals do so because they are unable or unwilling to organize themselves effectively to monitor and select published information. Summary and titles journals help these people. If such secondary journals are not effective enough, criticism should be directed at them, not at the source publications.

$$
\text { Yours faithfully, }
$$

3 Erpingham Road,

G. B. SноRTER

London SW15.

\section{Hunting Down Pornography}

SIR,-It has apparently (Nature, 228, 203; 1970) been proved to the scientific mind's satisfaction that the hunting down of pornography by proper authorities is no more useful than was the annual hunting of eagles by members of some American Indian tribe who, by the way, were careful not to destroy the species.

But the missionary zeal of your Washington corres. pondent in committing assorted politicians to the secular hell of perversion is somewhat disturbing, especially when one remembers what happened to tribes who lost their taboos as a result of well meaning mission work.

Yours faithfully,

$$
\text { J. F. FoncIN }
$$

19 Avenue du Général-Leclerc,

Brie-Comte-Robert,

Seine-et-Marne, France. 